\title{
SYNTHESIS OF PYRROLIZINES BY INTRAMOLECULAR CAPTURE OF 1,4-DIPOLAR INTERMEDIATES IN REACTIONS OF ENAMINES WITH DIMETHYL ACETYLENEDICARBOXYLATE
}

\author{
W. Verboom, G. W. Visser, W. P. TrompenaArs \\ and D. N. REINHOUDT* \\ Laboratory of Organic Chemistry, Twente University of Technology, Enschede, The Netherlands \\ and \\ S. HaRkema and G. J. VAN Hummel \\ Laboratory of Chemical Physics, Twente University of Technology, Enschede, The Netherlands
}

(Received in UK 16 March 1981)

\begin{abstract}
Abetract-Solvent polarity and reaction temperature strongly influence the reactions of dimethyl acetylenedicarboxylate (DMAD) with 1-pyrrolidinyl enamines of acyclic and cyclic ketones. Whereas DMAD and 1-[1-phenyl-2(phenylthio)ethenyl]pyrrolidine (3) give only a mixture of the isomeric 1,3-butadienes (5) in apolar solvents, in methanol the main product is the pyrrolizine 7. together with 5 . Again in methanol, DMAD reacts at $0-5^{\circ}$ with 8,9 and 10 to give exclusively $1: 1$ adducts, the pyrrolizines 11,12 and 13, respectively, whereas at $-50^{\circ} 8$ and 9 give 1:2 (enamine:DMAD) adducts, the pyrrolizines 14 and 15 , respectively; a single crystal X-ray analysis of 14 gave the structure of the 1:2 adducts. In the same solvent methyl propiolate and 8 give only the linear Michael adduct 17. The enamine-ketone 18 reacts with DMAD in propylene carbonate at $0-5^{\circ}$ to give, via $(2+2)$-cycloaddition and ring expansion, 19, and the linear Michael adduct 20. The mechanism of $(2+2)$-cycloaddition and pyrrolizine formation is discussed in terms of a common tied-ion pair intermediate formed in the first, rate-determining step. followed by a second solvent-dependent step.
\end{abstract}

An obvious and simple synthesis of cyclobutene derivatives comprises the thermal $(2+2)$-cycloaddition reaction of alkenes and acetylenes.' In practice it has been found that only reactants in which both $2 \pi$-electron systems are strongly polarized and in which the electron densities are opposite undergo this type of cycloaddition under relative mild conditions. Although a few cyclobutenes have been synthesized by reaction of electron-rich acetylenes (ynamines) with electron-deficient olefins such as acrylonitriles ${ }^{2}$ and nitro-alkenes, ${ }^{3}$ most cyclobutenes have been obtained from electron-deficient acetylenes and electron-rich alkenes either in the presence ${ }^{4}$ or in the absence ${ }^{5.6}$ of a Lewis acid catalyst. Lewis acid-catalyzed thermal $(2+2)$-cycloaddition of this type can take place with simple unactivated olefins but the non-catalyzed reactions require electron-donating alkoxy or (dialkyl)amino substituents.

The first synthesis of 3-dialkylamino cyclobutenes by the reaction of enamines and acetylenic esters was nearly simultaneously reported by three groups. ${ }^{7-9}$ Since the 3-dialkylaminocyclobutenes undergo facile ring opening, the reaction of acetylenic esters with enamines of cyclic ketones has frequently been applied in ring enlargement reactions. ${ }^{10-14}$

An investigation of the effect of solvent polarity on the reaction between 3-(1-pyrrolidinyl)thiophenes (1) and dimethyl acetylenedicarboxylate (DMAD) revealed a remarkable solvent dependency. ${ }^{15}$ In apolar solvents such as toluene the expected formation of $(2+2)$-cycloadducts was observed, but in polar protic and aprotic solvents such as methanol and acetonitrile 6,7,7a,8 tetrahydro $-5 H$ - thieno $-[2,3-b]$ pyrrolizines $(2, \mathrm{E}=$ $\left.\mathrm{COOCH}_{3}\right)$ were formed. Since we regard 3-(1-pyr- rolidinyl)thiophenes (1) as heteroaromatics with "enamine" reactivity we have subsequently investigated the influence of solvent polarity on reactions of enamines<smiles>[R]c1scc(N2CCCC2)c1[R]</smiles><smiles>[R]c1sc2c(c1[R])N1CCC[C@]1(F)[C@H]2F</smiles>

of acyclic and cyclic ketones with acetylenic esters and the results of this work are the subject of this paper.

\section{RBSULTS 16}

The $\mathrm{C}=\mathrm{C}$ double bond of the enamine $1-[1-$ phenyl -2 - (phenylthio)ethenyl]pyrrolidine (3) is very similar to the reactive $\mathrm{C}-2-\mathrm{C}-3$ bond in the 3-(1-pyrrolidinyl)thiophenes (1) that exhibit the spectacular effect of the solvent in reactions with DMAD. This enamine was prepared by acid-catalyzed reaction of 1-phenyl-2-(phenylthio)ethanone ${ }^{17}$ with pyrrolidine in a yield of $84 \%$. Subsequent reaction with DMAD in diethyl ether at room temperature gave a mixture of two isomeric $1: 1$ adducts (73\%). ${ }^{1} \mathrm{H}$ NMR and ${ }^{13} \mathrm{C}$ NMR spectroscopic data exclude a cyclobutene structure such as 4 and are in good agreement with two isomeric 1,3-butadiene structures (5, ratio 3:2). Despite careful analysis of the spectra it remains difficult to exclude the alternative 1,3 . butadienes 6 that can result from Michael addition of 3 to DMAD. However comparison of our data (Experimental) 


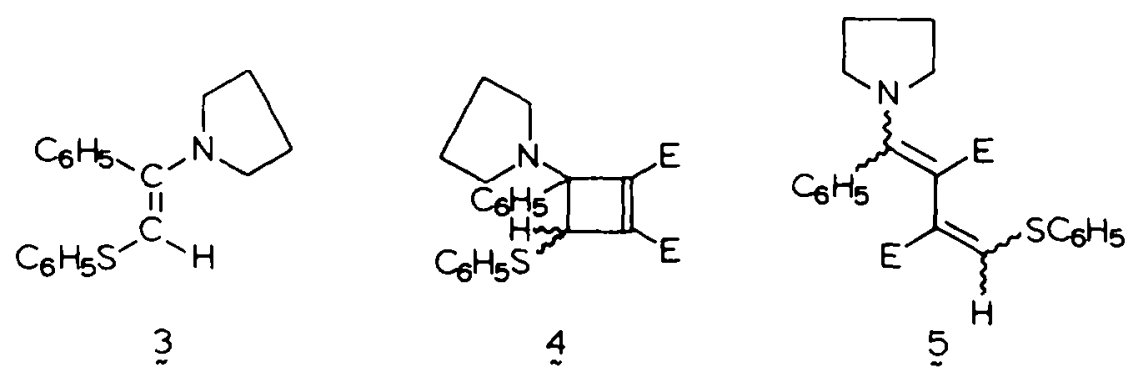<smiles></smiles>

with those reported for the products obtained from a corresponding reaction of 2-dimethylamino-2-methylthiostyrene by Karlsson and Sandstroem ${ }^{18}$ indicate that the 1,3-butadienes are of type 5 .

The reaction of 3 with DMAD in methanol at $35^{\circ}$ for $16 \mathrm{hr}$ yielded two fractions. The first was obtained in $60 \%$ yield as a yellow crystalline compound that was shown to be 5,6,7,7a - tetrahydro - 1 - (methoxycarbonyl) - 3 - phenyl - 2 - (phenylthio) - $1 \mathrm{H}$ - pyrrolizine - 1 . acetic acid methyl ester (7). The absorptions in the ${ }^{1} \mathrm{H}$ NMR spectrum at $\delta 4.72 \mathrm{ppm}$ (dd, $J=6$ and $10 \mathrm{~Hz}$ ) and at $\delta 3.62$ and $2.59 \mathrm{ppm}(\mathrm{AB}$-quartet, $J=17 \mathrm{~Hz})$ are in excellent agreement with values of the corresponding $\mathrm{H}-7 \mathrm{a}$ and $\mathrm{CH}_{2} \mathrm{E}$ signals in the ${ }^{1} \mathrm{H}$ NMR spectra of the thieno [2,3-b]pyrrolizines (2), the structure of which was unequivocally established by $\mathrm{X}$-ray analysis. ${ }^{15}$

The second fraction (27\%) consisted of the two isomeric 1,3-butadiene derivatives (5, ratio $3: 2$ ). This result resembles the reactions of $3-(1$-pyrrolidinyl)thiophenes (1) and DMAD in polar aprotic solvents such as nitromethane and acetonitrile in which competitive $(2+$ 2)-cycloaddition and pyrrolizine formation take place. ${ }^{19}$ In these latter reactions a substantial effect of reaction temperature on the ratio of the two products was observed. Consequently, the effect of the reaction temperature on the ratio of 7 to 5 was investigated. Equimolar amounts of 3 and DMAD in methanol were reacted at three different temperatures $n^{\circ}: 20^{\circ}$ and $40^{\circ}$ and the ratio of 7 to 5 was determined in the irude reaction mixture by glc. The results given in the tatie : how that the formation of the pyrrolizine 7 is faycured by higher temperatures with the ratio of 7 to 5 increasing from 0.9 at $0^{\circ}$ to 1.75 at $40^{\circ}$.

The results of these experiments clearly show that for reactions of enamines and DMAD two different types of reaction are possible and that the relative rates are dependent on the polarity of the solvent and the reaction temperature ${ }^{20}$ The reason why hitherto only one type of reaction viz $(2+2)$-cycloaddition had been found is a consequence of the apolar solvents generally employed. Such solvents were used because it was considered that they enhanced $(2+2)$-cycloaddition and suppressed linear addition. ${ }^{20}$

Since the reaction in methanol represents a novel simple synthesis of pyrrolizintes and because this

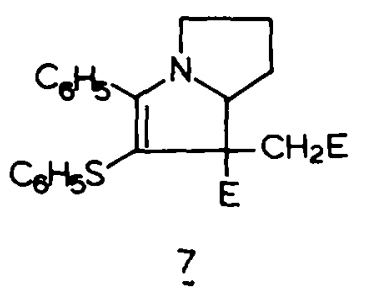

Table 1. Product distribution 7 to 5 in reactions of 3 and DMAD in methanol at different temperatures*

\begin{tabular}{rc}
\hline Temp. ${ }^{b}\left({ }^{\circ} \mathrm{C}\right)$ & Ratio $2 / 5$ \\
\hline 0 & 0.9 \\
20 & 1.36 \\
40 & 1.75 \\
\hline
\end{tabular}

a Molar rat1o 3 to DMAD (1:1): the rat1o 7 to 5 was determinêd by GLC (5: OV-101).

b At lower temperatures the reaction of 3 and DMAD becomes to slow.

heterocyclic ring system constitutes a part of many natural products, ${ }^{24}$ we have explored the scope of this reaction with particular emphasis on enamines of cyclic ketones. The latter because of our interest in the synthesis of analogues of mitomycin $\mathrm{C}$, a promising anticancer agent in which the $1 H$-pyrrolo[1,2-a]indole skeleton is present.

Reactions of enamines of cyclic ketones with acetylenic esters in apolar solvents are well documented. ${ }^{1.5}$ Huebner et al. ${ }^{9}$ have reported that 1-(1-pyrrolidinyl)cyclopentene (8) reacts with ethyl propiolate in diethyl ether at $\infty^{\circ}$ to give the corresponding $(2+2)$ cycloadduct and Berchtold and Uhlig and Yoshii and Kimoto $^{25}$ have described similar reactions with DMAD and methyl tetrolate in toluene. Reaction of 1-(1-pyrrolidinyl)-cyclohexene (9) with DMAD in diethyl ether at $25-35^{\circ}$ gave the corresponding bicyclo[4.2.0]oct - 7 - ene 7,8 - dicarboxylate in $76 \%$ yield, and 1 - $(3,4$ - dihydro - 1 - naphthyl)pyrrolidine (10) reacted similarly. ${ }^{16}$

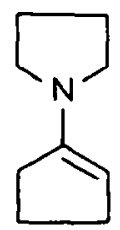

8<smiles>C1=C(N2CCCC2)CCCC1</smiles>

9<smiles>C1=C(N2CCCC2)c2ccccc2CC1</smiles> 
The three enamines (8, 9 and 10) reacted with an cquimolar amount of DMAD in methanol at temperatures of $0-5^{\circ}$ for $16 \mathrm{hr}$ to give the corresponding cyclopenta[b]pyrrolizine (11), the $1 H$-pyrrolo[1,2-a]indole (12) and the $6 \mathrm{H}$ - benzo[g]pyrrolo $[1,2$ - a ]indole (13) as the only products obtained in yields of 30,67 and $89 \%$, respectively. The structures were proven by mass spectrometry, ' $\mathrm{H}$ an ${ }^{13} \mathrm{C}$ NMR spectroscopy and elemental analysis. The $\mathrm{N}-\mathrm{CH}-$ and $\mathrm{CH}_{2} \mathrm{E}$ signals of 11-13 resonate characteristically at $\delta 4.55 \pm 0.15 \mathrm{ppm}$ (dd, $J=6$ and $10 \mathrm{~Hz}$ ) and at $\delta 3.35 \pm 0.15 \mathrm{ppm}$ and $\delta 2.55 \pm$ $0.12 \mathrm{ppm}(J=17 \mathrm{~Hz})$, respectively in their 'H NMR spectra, indicating that in each case only one diastereoisomer has been formed. $t$ These values correspond with those found for thieno[2,3-b]pyrrolizines (2): $\delta(\mathrm{H}$ 7a) $4.80 \pm 0.10 \mathrm{ppm}$ and $\delta\left(\mathrm{CH}_{2} \mathrm{E}\right) 3.30 \pm 0.05 \mathrm{ppm}$ and $3.02 \pm 0.05 \mathrm{ppm}$. The large difference $(-0.5 \mathrm{ppm})$ in the chemical shift of one of the $\mathrm{CH}_{2} \mathrm{E}$ protons and almost no difference in the chemical shift of the other proton can be attributed to a deshielding effect by the thiophene ring on one of the $\mathrm{CH}_{2} \mathrm{E}$ protons of 2 . X-Ray analysis of 2 $\left(R^{1}=\mathbf{H}\right.$ and $\left.R^{2}=0-C_{3} O_{6} H_{4}\right)$ has shown that the $\mathrm{CH}_{2} \mathrm{E}$ group and the pyrrolidine ring are cis. Moreover, comparison with the ${ }^{1} \mathrm{H} N M R$ and ${ }^{13} \mathrm{C}$ NMR data of compound 14 (vide infra), the stereochemistry of which was assigned by $X$-ray analysis, point to the same stereochemistry $\left(\mathrm{CH}_{2} \mathrm{E}\right.$ and pyrrolidine ring cis).

tThe ${ }^{13} \mathrm{C}$ NMR spectrum of 12 shows two sets of absorptions; a fact we cannot account for.
The formation of 13 was shown to be largely temperature independent but at $-10^{\circ}$ the reaction becomes slow. The same was observed in reaction of 3 with DMAD (Table). However in the case of 8 and 9, the reaction at $-50^{\circ}$ in methanol also produced $2: 1$ adducts (DMAD: enamine). With two equivalents of DMAD these compounds become the major isolated products in $50 \%$ (14) and $46 \%$ (15) yield respectively together with $9 \%$ of 11 and $33 \%$ of 12 , respectively. The ${ }^{1} \mathrm{H}$ NMR spectroscopic data of 14 and 15 resemble those of the corresponding pyrrolizines 11 and 12 with absorptions at $\delta 4.87 \mathrm{ppm}$ (dd, $J=6$ and $9 \mathrm{~Hz}$ ) in 14 and $\delta 4.51 \mathrm{ppm}$ (dd, $J=6$ and $9 \mathrm{~Hz}$ ) in 15 . The $\mathrm{CH}_{2} \mathrm{E}$ groups resonate at $\delta$ 3.19 and $2.71 \mathrm{ppm}(J=17 \mathrm{~Hz})$ in 14 and $\delta 3.30$ and $2.51 \mathrm{ppm}(J=17 \mathrm{~Hz})$ in 15 and their ${ }^{13} \mathrm{C}$ NMR spectra also indicate the presence of a pyrrolizine ring. An additional AB-quartet was evident in their ${ }^{1} \mathrm{H}$ NMR spectra as were two additional $\mathrm{sp}^{2}$-hybridized carbon atoms in their ${ }^{13} \mathrm{C}$ NMR spectra. However, further structural assignments for the compounds could not be made with the spectral data on hand. X-Ray diffraction showed that the compound obtained from 8 was 14 (see Fig. 1) and it follows that the compound obtained from 9 was 15. The crystal structure of 14 was solved by direct methods ${ }^{26}$ (Experimental).

A perspective view of the molecule is given in Fig. 1 made by ORTEP. ${ }^{27}$ The non-equivalence of the protons of the $=\mathrm{C}-\mathrm{CH}_{2} \mathrm{E}$ group at C.3 in 14 and 15 is due to steric hindrance by the $\mathrm{NCH}_{2}$ group of the pyrrolizine ring (see 16). It is interesting to note that also in this pyrrolizine the $\mathrm{CH}_{2} \mathrm{E}$ and the pyrrolizine ring are cis. ${ }^{15}$ The effect of

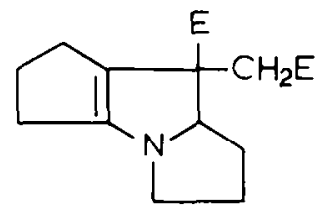

11<smiles>FCC1(F)C2=C(CCCC2)N2CCCC21</smiles>

12<smiles>FCC1(F)C2=C(c3ccccc3CC2)N2CCCC21</smiles><smiles>FCC(F)=C1CCC2=C1N1CCC[C@H]1C2(F)F</smiles>

14<smiles>CC(F)=C1CCCC2=C1N1CCCC1C2(F)CF</smiles>

15

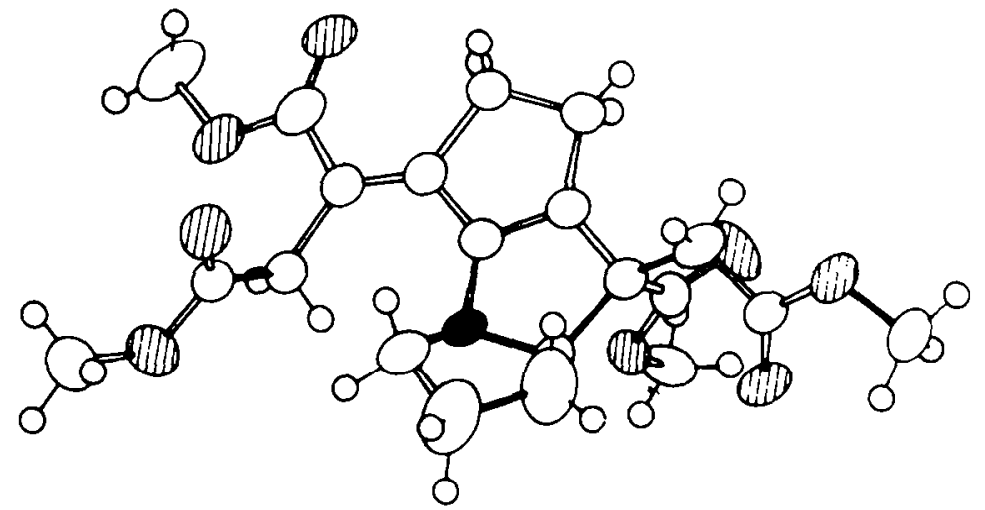

Fig. 1. Computer drawing of compound 14. 
changes in the solvent polarity and in the nature of the acetylene and of the enamine were next studied. Methyl propiolate reacted with 8 in methanol at $-20^{\circ}$ to give a single product, the linear Michael adduct 17 in $73 \%$ yield. Similar type of compounds have been described by Brannock et al. ${ }^{21}$ and by Doyle ${ }^{28}$ as the results of a slow<smiles>CC1=C(F)C(F)(F)[C@@H]2CCC3CC=C1N32</smiles>

16

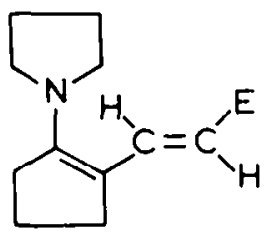

17 isomcrization of initially formed $(2+2)$-cycloadducts. They have explained their formation by a slow $(2+2)$ cycloreversion of the $(2+2)$-cycloadduct, followed by Michael addition. This means that in the apolar solvents used the $(2+2)$-cycloadduct is the kinetically controled product and consequently the Michael addition is much slower than the $(2+2)$-cycloaddition. It would appear that the formation of pyrrolizines is limited to reactions of 1-(1-pyrrolidinyl) cycloalkenes since 1-(1-piperidinyl)and 1-(4-morpholinyl)cyclohexene react with DMAD at various temperatures to give only mixtures of $(2+2)$ cycloaddition products and Michael adducts. Similar results were found in reactions of 3-(1-piperidinyl)- and 3-(4-morpholinyl)-thiophenes. ${ }^{15}$

The infuence of the solvent polarity was investigated in more detail by reacting 9 and DMAD in a series of polar non-protic solvents. The resulting pyrrolizine 12 and the $(2+2)$-cycloadduct (or the corresponding cycloocta-1,3-diene) ${ }^{7}$ were estimated by ${ }^{1} \mathrm{H}$ NMR spectroscopy. These experiments showed that the yield of pyrrolizine 12 decreases in the order: methanol $>$ formamide > propylene carbonate > acetonitrile > nitromethane.

As part of our work on the synthesis of analogues of mitomycin $\mathrm{C}^{29}$ we are currently investigating the synthesis of substituted $1 H$-pyrrolo[1,2-a]indoles by reacting DMAD with enamines of substituted cyclohexanones, in methanol. Since in milumycin $\mathrm{C}$ a 5,8 - dioxo - $1 H$ - pyrrolo[1,2 - a]indole skeleton is present we are investigating methods to introduce the required 5-, and 8-keto functions. The reaction of 5,5 - dimethyl - 3 - (1 pyrrolidinyl) - 2 - cyclohexen - 1 - one (18) with DMAD in methanol at $-60^{\circ}$ was first studied. ${ }^{1} \mathrm{H}$ NMR spectroscopy showed ...st only $(2+2)$-cycloaddition and Michael addition had taken place. In propylene carbonate at $0-5^{\circ}$ a similar result was found; only the cycloocta-1,3-diene $19^{9,30}$ and the Michael adduct 20 were isolated in 10 and $37 \%$ yield, respectively.

\section{Discussion}

The mechanism of the thermal $(2+2)$-cycloaddition of acetylenes and olefins has to our knowledge not been studied in detail. ${ }^{31}$ This is in sharp contrast with the corresponding $(2+2)$-cycloaddition of electron-rich alkenes with electron-deficient alkenes which has been extensively studied by Huisgen et al. ${ }^{33}$ This work has provided conclusive evidence for a two-step reaction via a 1,4-dipolar intermediate and in analogy with these reactions, the reactions between acetylenic esters and enamines in apolar solvents have generally been interpreted as being two-step processes involving 1,4-dipolar intermediates. The argument is based firstly on the prediction by Woodward and Hoffmann ${ }^{34}$ that concerted thermal $(2+2)$-cycloaddition reactions are either symmetry-forbidden or unlikely for steric reasons and secondly on the predicted stabilization of the 1.4-dipoles formed by the substituents (NR'R and COOR). However, a concerted formation of the cyclobutene, which involves some degree of bonding in both $\sigma$-bonds in the transition state, cannot be excluded on the basis of the orbital symmetry arguments used for the cyclobutane formation. ${ }^{33}$

A qualitative Frontier Molecular Orbital (FMO) treatment of a concerted thermal $(2+2)$-cycloaddition of an acetylene and an olefin involve the interaction of the lowest unoccupied (LUMO) and highest occupied (HOMO) molecular orbitals of the olefin and acetylene, assuming that the transition state will resemble the reactants in an exothermic reaction. ${ }^{34}$ Overlap of these orbitals is possible with interacting acetylenes and alkenes both in the XZ- and XY-planes (as with ketenes) and this makes the situation for a concerted process fundamentally different from reactions between two olefins ${ }^{33}$ because the efficiency of the overlap of orbitals in the perpendicular $\mathrm{XZ}$ - and $\mathrm{XY}$-planes will be much lower than overlap of orbitals in the same plane (Scheme 1a) as is the case where two olefins are reacting. Only when the coefficients of these orbitals are large this type of overlap will contribute to the bonding in an early stage of the reaction and this will be the case in reactions of electron-rich alkenes with electron-deficient acetylenes for which the interaction of the LUMO of the acetylene and the HOMO of the alkene dominates (Scheme 1b). Another case where a concerted $(2+2)$-cycloaddition is possible according to this FMO treatment, is the reaction of an electron-rich acetylene with an electron-deficient olefin because then the HOMO (acetylene)-LUMO (olefin) interaction will be the most important one ${ }^{3}$ (Scheme 1c). This type of pericyclic reaction is neither a ${ }_{\pi} 2_{3}+{ }_{\pi} 2_{a}$ or a ${ }_{\pi} 2_{3}+{ }_{\pi} 2_{3}$ cycloaddition but can be defined as a $2_{s}+2 n$ ( $n=$ nodal) process. This theory also explains the stereochemistry of the two aforementioned kinds of thermal $(2+2)$-cycloaddition since the alter-

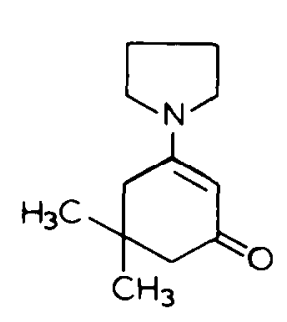

18

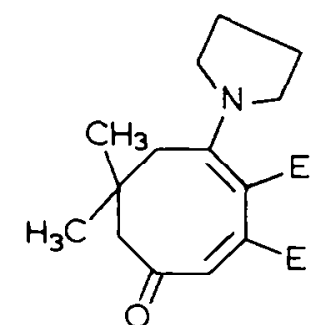

$\stackrel{19}{2}$<smiles>CC1(C)CC(=O)C(C(F)=CF)=C(N2CCCC2)C1</smiles>

20 


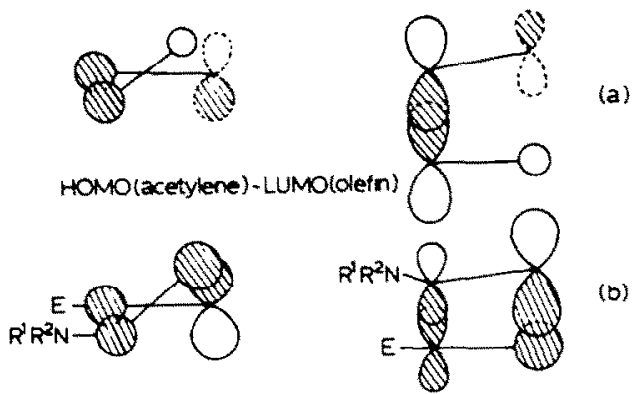

LUMO(electron-deficient acetylene)/HOMO(electron-rich olefin)
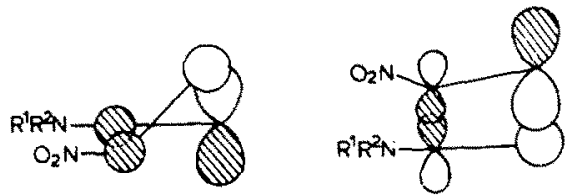

(c)

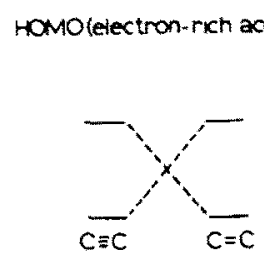

(a)

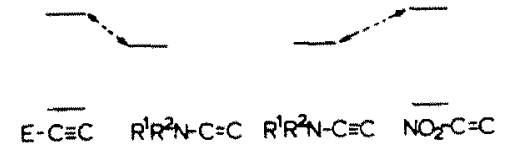

(b)

(c)

Scheme 1. Frontier molecular orbitals of substituted alkenes and substituted acetylenes.

native orientation would not benefit from the large orbital coefficients in the "perpendicular" overlap.

If we analyze the results we have obtained and when the known reactions of DMAD and enamines are also taken into account we can distinguish three different reaction products: $(2+2)$-cycloadducts, Michael adducts and pyrrolizines. Of the latter two types can be formed, either of a $1: 1$ or a $1: 2$ molecular composition. The formation of both the Michael adducts and the pyrrolizines can be rationalized by assuming the intermediacy of a common 1,4-dipolar charge-separated species 21 which results from nucleophilic addition of the electron-rich enamine to the electron-deficient $C=C$ triple bond of the acetylene. Intermolecular proton transfer, most probably via the solvent, gives the Michael adduct (eg. 17) and, where the steric situation is favourable, intramolecular proton abstraction gives an allyl azomethinylid (22, for a detailed discussion see Ref. 15).
This azomethinylid undergoes tautomerization and the tautomeric 1,5 -dipolar intermediate 23 then cyclizes via a symmetry-allowed disrotatory electrocyclization. ${ }^{37}$ The spectroscopic data of $\mathbf{2}$ and 14 show that only one isomer is formed, and this means that the stereochemistry in the 1,5-dipolar intermediate $\mathbf{2 3}$ must be as depicted in Scheme 2.

In addition to these two proton abstraction processes by the carbanion in 21 a third possibility exists if the enamine has a proton (or two) at the $\beta^{\prime}$-position. This is the case in enamines 8 and 9 but not in 1, 3 or 10. For reasons discussed below, at lower temperatures in the intermediates formed by the addition of 8 or 9 to DMAD a third type of prototropic shift (Scheme 3) which converts the dipolar intermediate into 24 , is a faster reaction than the formation of 22 . The dienamine 24 finally reacts via route $b$ (Scheme 2 ) with a second molecule of DMAD to give the pyrrolizines 14 and 15.

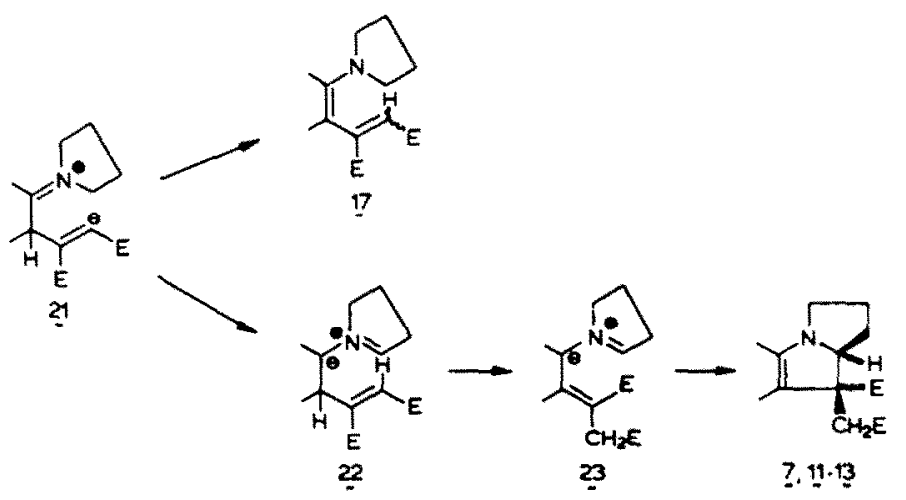

(a)

Scheme 2. 


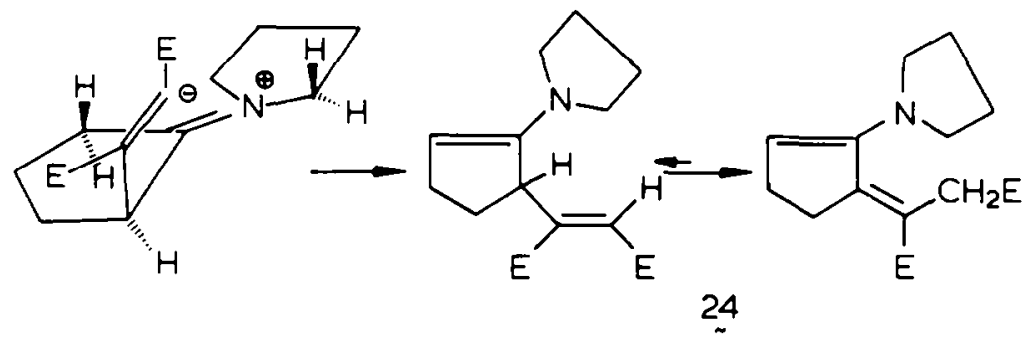

Scheme 3.

As mentioned before, 1,4-dipolar intermediates like 21 have been proposed by Huebner et al., Hafner et al., ${ }^{30}$ Anghelide et al., ${ }^{39}$ Fleury $e t$ al. ${ }^{22}$ and others as the intermediates in the formation of the $(2+2)$-cycloadducts. However, convincing evidence for this type of mechanism has not been provided. Eberbach and Carré ${ }^{23}$ found that the ratio in which the Michael adduct and the $(2+2)$-cycloadduct are formed depends on the polarity of the solvent but that the rate of conversion of DMAD and the enamine was almost independent of the solvent polarity. This led them to conclude that a common 1,4-dipolar intermediate is formed in the rate determining step, followed by a second step in which the products are formed which is solvent dependent. Although we did not measure the rates of the reactions of enamines and DMAD it was evident that the rate of conversion hardly differs in a strongly polar solvent like methanol and in solvents such as toluene or benzene. ${ }^{15}$ Based on this observation and the fact that Huisgen found enormous rate differences for the reaction of tetracyanoethylene (TCNE) with enol ethers in polar and apolar solvents $\left(k_{\text {(aceionitrile) }} / k_{\text {(cyclonexane) }} 1-6 \times 10^{4}\right)^{33}$ it can be concluded that the formation of a charge-separated 1,4dipolar intermediate is not the rate determining step in our case. Further, Huisgen showed that the 1,4-dipolar intermediates formed in the reaction of enol ethers and TCNE, under conditions of kinetic control, in apolar solvents could be trapped by an intermolecular reaction with 1,4-dipolarophiles. ${ }^{33}$ In our reactions, if such 1,4 dipolar intermediates were involved, interception by an intramolecular proton abstraction process in apolar solvents should be evident in cases where this is the prefered process in polar solvents. Since we have shown ${ }^{15}$ that the proton abstraction is an intramolecular process it will be virtually independent of the polarity of the solvent. Therefore we conclude that in apolar solvents the reactioni of enamines and DMAD does not proceed via a charge-separated 1,4-dipolar intermediate as has always been hi ... to proposed in the literature. If the reaction is a two-step process there must be, to some degree, restricted rotation of the two poles of the 1,4dipole, probably caused by electrostatic interaction (e.g. in a tied-ion pair as depicted in Scheme 3). Alternatively, the reaction in apolar solvents might be a near-concerted process which means that there is some degree of bonding in both $\sigma$-bonds in a highly polarized transition state. We regard the difference between both possible pathways as being philosophical because it concerns the definition of bonding.

In polar solvents the conversion of an initially formed tied-ion pair type of 1,4-dipolar intermediate into a charge-separated type will be assisted by solvation by solvent molecules. This process can become the favoured pathway over $(2+2)$-cycloaddition and this would explain how the different products are formed.
For further reaction of a charge-separated ion pair type of intermediate 21 there are various possibilities: intermolecular prototropic processes will produce Michael adducts and intramolecular proton abstraction gives either the alkylated enamine 24 or the allyl azomethinylid 22 which subsequently leads to the pyrrolizines. According to our results the mode of intramolecular proton abstraction depends on the temperature and alkylation takes place only at low temperature. This can be explained if we compare the acidity of the two methylene groups that donate the protons. In the 1,4dipolar species we assume that most of the positive charge is located on the nitrogen atom and consequently the $\mathrm{C}=\stackrel{\oplus}{\mathrm{N}}-\mathrm{CH}_{2}-$ protons will be more acidic than the protons of the $\mathrm{CH}_{2}-\mathrm{C}=\stackrel{\oplus}{\mathrm{N}}$ /group. On the other hand proton abstraction of the latter protons requires less rotation of the intermediate (Fig. 2). Therefore at low temperature

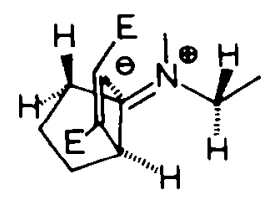

Fig. 2.

the proton abstraction takes place under kinetic control and at high temperature under conditions of thermodynamic control. When the steric situation for intramolecular proton abstraction is not favourable, intermolecular protontransfer will be the preferred pathway. This would explain why only pyrrolidine enamines are capable of undergoing intramolecular proton abstraction in contrast with enamines of 6 -membered amines. $^{15}$

The reaction of 18 and DMAD both in methanol and propylene carbonate illustrates a further possibility. As shown in Fig. 3 in this case an alternative proton donor, viz the enol group, is available and in this situation the formation of a Michael adduct is more favourable than pyrrolizine formation.<smiles></smiles>

Fig. 3. 
The effect of the temperature on the ratio of $(2+2)-$ cycloadduct 5 and pyrrolizine 7 (Table) reflects the differences, at various temperatures, in energy barriers that separate the tied-ion pair 1,4-dipolar intermediate and the charge-separated 1,4-dipole and $(2+2)$-cycloadduct, respectively. It can be expected that the activation entropy for the $(2+2)$-cycloaddition has a larger negative value than for the formation of a "linear" 1,4-dipole in protic polar solvents ${ }^{t 0}$ and this agrees with the observed increase of pyrrolizine formation with increasing reaction temperature.

\section{EXPERIMENTAL}

M.ps were determined with a Mettler FP1 apparatus and are uncorrected. ${ }^{1} \mathrm{H}$ and ${ }^{13} \mathrm{C}$ NMR spectra were recorded with a Bruker WP8OFT and a Varian XL-100 spectrometer, respectively, in $\mathrm{CDCl}_{3}$ with TMS as internal standard. Mass spectra were obtained with a Varian Mat 311A spectrometer and IR spectra with a Perkin Elmer 257 spectrophotometer. Elemental analyses were carried out by the Element Analytical section of the Institute for Organic Chemistry TNO, Utrecht, The Netherlands, under the supervision of W. J. Buis.

Dimethyl acetylenedicarboxylate (DMAD) refers to Aldrich reagent and was distilled before use. Methyl propiolate (Fluka) was used without further purification. Compounds $8,0^{2}, 9^{12} 16^{43}$ and $18^{4}$ were prepared according to known methods.

Preparation of $1-[1$ - phenyl - 2(phenylthio)ethenyl]pyrrolidine (3)

A soln of 1 - phenyl - 2 - (phenylthio)ethanone ${ }^{17}(4.56 \mathrm{~g}$, $0.20 \mathrm{~mol})$, pyrrolidine $(21.3 \mathrm{~g}, 0.30 \mathrm{~mol})$ and $p$-toluenesulfonic acid $(1 \mathrm{~g})$ in $125 \mathrm{ml}$ benzene was refluxed for $5 \mathrm{hr} ; 4.2 \mathrm{ml}$ water was separated in a Dean-Stark trap. After evaporation of the solvent and most of the excess of pyrrolidine under reduced pressure, the light brown enamine 3 was purified by clution with $\mathrm{MeOH}$. Recrystallization from petroleum-ether $(60 / 80)$ afforded white crystals.

Yield 84\%; m.p. 88.6-89.8 ; 'H NMR: $\delta 7.4-7.0$ (m, $10 \mathrm{H}, \mathrm{Ar}), \delta$ $4.79(\mathrm{~s},=\mathrm{CH}), \delta 3.25-3.05\left(\mathrm{~m}, 4 \mathrm{H}, \mathrm{N}-\mathrm{CH}_{2}\right)$ and $\delta 2.0-1.8(\mathrm{~m}, 4 \mathrm{H}$, $\left.-\mathrm{CH}_{2}\right) .{ }^{13} \mathrm{C}$ NMR: $\delta 157.0(\mathrm{~s}, \mathrm{~N}-\mathrm{C}=), \delta 142.4$ and $137.1(\mathrm{~s}, \mathrm{Ar}), \delta$ 128.3, 128.1, 127.7, 124.8 and $123.6(\mathrm{~d}, \mathrm{Ar}), \delta 80.5$ (d, N-C=C-), $\delta$ $48.9\left(\mathrm{t}, \mathrm{N}-\mathrm{CH}_{2}\right)$ and $\delta 25.1\left(\mathrm{t},-\mathrm{CH}_{2}\right)$. MS: $\mathrm{M}^{+} 281.124$, calc. 281.124. (Found: C, 76.77; H, 6.81; N, 4.90 and S, 11.40. Calc. for $\mathrm{C}_{18} \mathrm{H}_{19} \mathrm{NS}$ (281.42): $\mathrm{C}, 76.82 ; \mathrm{H}, 6.81 ; \mathrm{N}, 4.98$ and $\mathrm{S}, 11.39 \%$ ).

Reactions of 1 - [1 - phenyl - 2 - (phenylthio)ethenyl]pyrrolidine (3) with DMAD in diethyl ether and methanol. Formation of 1 phenyl - 4-(phenylthio) - 1 - (1 - pyrrolidinyt) - 1,3-butadiene . 2,3 - dicarboxylic acid dimethyl ester (5) and 5,6,7,7a - tetrahydro - 1 - (methoxycarbonyl) - 3 - phenyl - 2 - (phenylthio) - 1 H pyrrolizine - 1 - acetic acid methyl ester (7)

Diethyl ether as a solvent. A soln of DMAD $(4.69 \mathrm{~g}, 33 \mathrm{mmol})$ in $30 \mathrm{ml}$ dry diethyl ether was added to a suspension of $3(8.43 \mathrm{~g}$. $30 \mathrm{mmol}$ ) in $70 \mathrm{ml}$ dry diethyl ether under $\mathrm{N}_{2}$ at room temp. The orange-red soln was stirred overnight at room temp and the resulting ppt was collected by filtration. Purification by elution with $\mathrm{MeOH}$ afforded the pure 5 as a mixture of isomers (2:3) in $73 \%$ yield.

Methanol as a solvent.45 A soln of DMAD $(8.5 \mathrm{~g}, 60 \mathrm{mmol})$ in $50 \mathrm{ml} \mathrm{MeOH}$ was added to a suspension of $3(8.43 \mathrm{~g}, 30 \mathrm{mmol})$ in $100 \mathrm{ml} \mathrm{MeOH}$ under $\mathrm{N}_{2}$ at $35^{\circ}$. After stirring overnight of the orange-red soln at $35^{\circ}$, the resulting ppt was collected by filtration. Purification by elution with $\mathrm{MeOH}$ yielded the light yellow 7 (yield $60 \%$ ). On standing overnight at $-20^{\circ}$ a yellow solid crystallized from the filtrate. Elution with $\mathrm{MeOH}$ and then recrystallization from $\mathrm{MeOH}$ gave the yellow 5 (yield 27\%) as a mixture of isomers (2:3).

Compound 5; m.p. $127-128^{\circ}$; 'H NMR: $\delta 7.5-6.9$ (m, $10 \mathrm{H}, \mathrm{Ar}$ ) $\delta 6.98$ and $6.40(\mathrm{~s},=\mathrm{CH}), \delta 3.79,3.65$ and $3.79,3.32\left(\mathrm{~s}, \mathbf{O C H}_{3}\right), \delta$ 3.3-3.1 (m, $\left.4 \mathrm{H}, \mathrm{N}-\mathrm{CH}_{2}\right)$ and $2.0-1.7\left(\mathrm{~m}, 4 \mathrm{H},-\mathrm{CH}_{2}\right) \cdot{ }^{13} \mathrm{C} \mathrm{NMR}$ : $\delta 169.1,167.9,167.7$ and $166.5(\mathrm{~s}, \mathrm{C}=0), \delta 159.6$ and $157.8(\mathrm{~s}$, $\mathrm{N}-\mathrm{C}=), \delta 147.7$ and $146.0(\mathrm{~d},=\mathrm{CH}-$ ), $\delta 125.8$ and $124.4 \mathrm{ls}$,
$-C(E)=1, \delta 99.1$ and $99.0(8, N-C=C)$ and $\delta 51.6,51.5,50.9$ and $50.6\left(\mathrm{OCH}_{3}\right.$ and $\left.\mathrm{N}-\mathrm{CH}_{2}\right)$. IR $(\mathrm{KBr}): 1688 \mathrm{~cm}^{-1}(\mathrm{C}=0)$. MS: $\mathrm{M}^{+}$ 423.152, Calc. 423.150. (Found: C, 67.99; H, 5.93; N, 3.28. Calc. for $\mathrm{C}_{24} \mathrm{H}_{25} \mathrm{NO}_{4} \mathrm{~S}$ (423.54): $\mathrm{C}, 68.06 ; \mathrm{H}, 5.95 ; \mathrm{N}, 3.31 \%$ ).

Compound 7; m.p. 134.5-135.5'; 'H NMR: $\delta$ 7.7-7.55 (m, $2 \mathrm{H}$, Ar), $\delta 7.45-7.25$ (m, 3 H, Ar), $\delta 7.25-7.0$ (m, 5 H, Ar), $\delta 4.72$ (dd,

$J=6 \pm 1$ and $10 \pm 1 \mathrm{~Hz}, \mathrm{~N}-\mathrm{CH}-), \delta 3.65$ and $3.23\left(\mathrm{~s}, \mathrm{OCH}_{3}\right), \delta$ 3.62 and $2.59\left(\mathrm{AB}-\mathrm{q}, J=17 \mathrm{~Hz}, \mathrm{CH}_{2} \mathrm{E}\right) .{ }^{13} \mathrm{C}$ NMR: $\delta 173.6$ and $172.3(\mathrm{~s}, \mathrm{C}=0), \delta 164.6(\mathrm{~s}, \mathrm{~N}-\mathrm{C}=), \delta 138.9$ and $131.9(\mathrm{~s}, \mathrm{Ar}), \delta$ $129.1,128.4,127.8,125.6$ and 124.7 (d, Ar), $\delta 96.1$ (s, N-C=C), $\delta$ $70.0\left(\mathrm{~d}, \mathrm{~N}-\mathrm{CH}-\right.$ ), $\delta 57.5$ [s, $\left.\mathrm{C}(\mathrm{E}) \mathrm{CH}_{2} \mathrm{E}\right], \delta 51.7$ and 51.6 (q, $\left.\mathrm{OCH}_{3}\right), \delta 50.2\left(\mathrm{t}, \mathrm{N}-\mathrm{CH}_{2}\right), \delta 37.9\left(\mathrm{t}, \mathrm{CH}_{2} \mathrm{E}\right)$ and $\delta 27.1$ and $24.6(\mathrm{t}$, $-\mathrm{CH}_{2}$ ). IR (KBr): $1736 \mathrm{~cm}^{-1}(\mathrm{C}=0)$. MS: $\mathrm{M}^{+} 423.147$, Calc. 423.150. (Found: C, 67.99; H, 6.02; N, 3.31; 0, 15.37; S, 7.59. Calc. for $\mathrm{C}_{24} \mathrm{H}_{25} \mathrm{NO}_{4} \mathrm{~S}$ (423.54): C, 68.06; H, 5.95; N, 3.31; $\mathrm{O}$, $15.11 ; \mathrm{S}, 7.57 \%$ ).

Reaction of 1 - (1 - pyrrolidinyl)cyclopentene (8), - cyclohexene (9) and 1 - (3,4 - dihydro - 1 - naphthyl) - pyrrolidine (10) with one equivalent of DMAD

Formation of the pyrrolizines 11-13. A soln of DMAD (7.38 g, $52 \mathrm{mmol}$ ) in $25 \mathrm{ml} \mathrm{MeOH}$ was added dropwise to a soln of 8-10 $\left(50 \mathrm{mmol}\right.$ ) in $75 \mathrm{ml} \mathrm{MeOH}$ under $\mathrm{N}_{2}$ at $0-5^{\circ}$. The red-colored soln was stirred overnight at room temp. For each enamine 8-10 a different workup-procedure was necessary. Compounds 11-13 were recrystallized from $\mathrm{MeOH}$.

1,2,3,5,6,7,7a,8 - Octahydro - 8 - (methoxycarbonyl) - cyclopenta[b]pyrrolizine - 8 - acetic acid methyl ester (11). After removing the $\mathrm{MeOH}$ under reduced pressure, repeated crystallization from $\mathrm{MeOH}$ at $-20^{\circ}$ gave a solid which on washing ( $3 \times 10 \mathrm{ml} \mathrm{MeOH}, 1 \times 10 \mathrm{ml}$ hexane) afforded 11 . Yield 30\%; m.p. 134-135 ; ' $\mathrm{H}$ NMR: $\delta 4.65$ (dd, $J=6 \pm 1$ and $10 \pm 1 \mathrm{~Hz}$, $\left.\mathrm{N}-\mathrm{CH}_{-}\right), \delta 3.68$ and $3.66\left(\mathrm{~s}, \mathrm{OCH}_{3}\right), \delta 3.21$ and $2.53(\mathrm{AB}-\mathrm{q}$, $\left.J=17 \mathrm{~Hz}, \mathrm{CH}_{2} \mathrm{E}\right) .{ }^{13} \mathrm{C}$ NMR: $\delta 176.4,174.1,172.5$ and $172.1(\mathrm{~s}$, $\mathrm{C}=0$ ), $\delta 159.1$ (s, N-C=), $\delta 119.1$ (s, N-C=C-), $\delta 70.9$ and 58.2 (d, $\mathrm{N}-\mathrm{CH}-\mathrm{f}, \delta 53.9$ and 49.7 (s, $-\mathrm{C}(\mathrm{E}) \mathrm{CH}_{2} \mathrm{E}$ ], $\delta 51.8$ and 51.6 (q, $\left.\mathrm{OCH}_{3}\right)$ and $\delta 36.6$ and $34.8\left(\mathrm{t}, \mathrm{CH}_{2} \mathrm{E}\right)$. $\mathrm{IR}(\mathrm{KBr}): 1740$ and $1720 \mathrm{~cm}^{-1}(\mathrm{C}=0)$ and $1660 \mathrm{~cm}^{-1}(-\mathrm{C}=\mathrm{C}-)$. MS: $\mathrm{M}^{+} 279.151$, Calc. 279.147. (Found: $\mathrm{C}, 63.60 ; \mathrm{H}, 7.57 ; \mathrm{N}, 4.81$. Calc. for $\mathrm{C}_{15} \mathrm{H}_{21} \mathrm{NO}$, (279.34): C, 64.50; H, 7.58; N, 5.01\%).

2,3,5,6,7,8,9,9a - Octahydro - 9 - (methoxycarbonyl) - $1 \mathrm{H}$ pyrrolo[1,2 - a]indole - 9 - acetic acid methyl ester (12). After evaporation of the solvent under reduced pressure, distillation of the crude mixture yielded 12 (b.p. $160-165 \% .7 \mathrm{~mm} \mathrm{Hg}$ ) as an oil which was crystallized from hexane as white crystals. Yield 67\%; m.p. $62-65^{\circ}$; ' $\mathrm{H}$ NMR: $\delta 4.45$ (dd, $J=6 \pm 1$ and $10 \pm 1 \mathrm{~Hz}, \mathrm{~N}-$ $\mathrm{CH}-$ ), $\delta 3.74$ and $3.68\left(\mathrm{~s}, \mathrm{OCH}_{3}\right), \delta 3.32$ and $2.43(\mathrm{AB}-\mathrm{q}$, $\left.J=17 \mathrm{~Hz}, \mathrm{CH}_{2} \mathrm{E}\right) .{ }^{13} \mathrm{C}$ NMR: $\delta 174.2$ and $172.2(\mathrm{~s}, \mathrm{C}=0), \delta 146.9$

I

(s, N-C=), $\delta 107.9$ (s, N-C=C-), $\delta 69.6$ (d, N-C H-), $\delta 57.4$ [s, $\left.-\mathrm{C}(\mathrm{E}) \mathrm{CH}_{2} \mathrm{E}\right), \delta 51.9$ and $51.5(\mathrm{q}, \mathrm{OCH}), \delta 48.5\left(\mathrm{t}, \mathrm{N}-\mathrm{CH}_{2}\right)$ and $\delta$ $36.9\left(t, \mathrm{CH}_{2} \mathrm{E}\right)$. IR (KBr): 1741 and $1718 \mathrm{~cm}^{-1}(\mathrm{C}=0)$ and $1670 \mathrm{~cm}^{-1}(-C=C-)$. MS: $M^{+} 293.162$, Calc. 293.163. (Found: $C$, $65.41 ; \mathrm{H}, 7.82 ; \mathrm{N}, 4.78 ; \mathrm{O}, 22.02$. Calc. for $\mathrm{C}_{16} \mathrm{H}_{23} \mathrm{NO}_{4}$ (293.37): $\mathrm{C}$, $65.51 ; \mathrm{H}, 7.90 ; \mathrm{N}, 4.77 ; 0,21.82 \%$ ).

$5,7,7 \mathrm{a}, 8,9,10$ - Hexahydro - 7 - methoxycarbonyl - $6 \mathrm{H}$ benzo[g]pymolo[1,2-a]indole - 7 - acetic acid methyl ester (13). In this case 13 crystallized spontaneously from the crude mixture. Filtration and washing $(3 \times 10 \mathrm{ml} \mathrm{MeOH})$ afforded 13 as white crystals. Concentration of the filtrate afforded another crop of 13 . Yield 89\%; m.p. 133-134'; 'H NMR: $\delta$ 7.45-7.1 (m, 4 H, Ar), $\delta$ 4.72 (dd, $J=6 \pm 1$ and $10 \pm 1 \mathrm{~Hz}, \mathrm{~N}-\mathrm{CH}_{\mathrm{H}}$ ), $\delta 3.70$ and 3.68 (s, $\left.\mathrm{OCH}_{3}\right), \delta 3.50$ and $2.66\left(\mathrm{AB}-\mathrm{q}, J=17 \mathrm{~Hz}, \mathrm{CH}_{2} \mathrm{E}\right) .{ }^{13} \mathrm{C}$ NMR: $\delta$ 173.5 and $172.1(\mathrm{~s}, \mathrm{C}=0), \delta 147.6(\mathrm{~s}, \mathrm{~N}-\mathrm{C}=), \delta 137.1(\mathrm{~s}), 129.4(\mathrm{~s})$, 127.4 (d), 127.1 (d) and 123.2 (d) (Ar), $\delta 112.9$ (s, N-C=C-), $\delta$

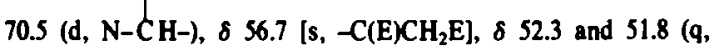
$\left.\mathrm{OCH}_{3}\right), \delta 51.8\left(\mathrm{t}, \mathrm{N}-\mathrm{CH}_{2}-\right.$ ) and $\delta 37.5\left(\mathrm{t}, \mathrm{CH}_{2} \mathrm{E}\right)$. IR $(\mathrm{KBr}): 1748$ and $1720 \mathrm{~cm}^{-1}(\mathrm{C}=0)$ and $1643 \mathrm{~cm}^{-1}(-\mathrm{C}=\mathrm{C}-)$. MS: $\mathrm{M}^{+} 341.164$, Calc. 341.163. (Found: C, 70.23; H, 6.86; N, 4.03. Calc. for $\mathrm{C}_{20} \mathrm{H}_{23} \mathrm{NO}_{4}$ (341.41): C, 70.36; $\mathrm{H}, 6.79 ; \mathrm{N}, 4.10 \%$ ). 
Reaction of 1 - (1 - pyrolidinyl)cyclopentene (8) with two equivalents of DMAD

Fomation of $[1,2,3,5,6,7,7 \mathrm{a}, 8$ - octahydo - 8 - (methoxycarbonyl) - 8 - (methoxycarbonylmethyl) - cyclopenta[b]pyrrolizin 3 - ylidene] - butanedioic acid dimethyl ester (14). A soln of 8 $(1.37 \mathrm{~g}, 10 \mathrm{mmol})$ in $20 \mathrm{ml} \mathrm{MeOH}$ was added dropwise to a soln of DMAD $(2.84 \mathrm{~g}, 20 \mathrm{mmol})$ in $30 \mathrm{ml} \mathrm{MeOH}$ under $\mathrm{N}_{2}$ at $-50^{\circ}$. The red-colored soln was stirred overnight at room temp. The $\mathrm{MeOH}$ was removed under reduced pressure and the residue was purified by column chromatography $\left(\mathrm{SiO}_{2}, \mathrm{CHCl}_{3}\right.$ : EtOAc $=$ $25: 7)$ yielding 14 as an oil which was crystallized from diethyl ether. GC-analysis (10\% SE-30) of the crude mixture showed in addition to 14 the presence of $8-10 \%$ of 11 , which could not be isolated by chromatography because of decomposition on silica. Yield 50\%; m.p. $144-145^{\circ}$; 1 H NMR: $\delta 4.87$ (dd, $J=6 \pm 1$ and $9 \pm 1 \mathrm{~Hz}, \mathrm{~N}-\mathrm{CH}-), \delta 3.75$ and $3.72\left(\mathrm{~s}, 3 \mathrm{H}, O \mathrm{CH}_{3}\right), \delta 3.69(\mathrm{~s}, 6 \mathrm{H}$, $\left.\mathrm{OCH}_{3}\right), \delta 4.05^{* 6}\left(\mathrm{AB}-\mathrm{q}, \mathrm{J}=17 \mathrm{~Hz},=\mathrm{C}-\mathrm{CH}_{2} \mathrm{E}\right), \delta 3.19$ and 2.71 $\left(\mathrm{AB}-\mathrm{q}, J=17 \mathrm{~Hz},-\mathrm{CH}_{2} \mathrm{E}\right) .{ }^{13} \mathrm{C}$ NMR: $\delta 173.1,172.2,171.4$ and $\mathrm{J} 67.9(\mathrm{~s}, \mathrm{C}=0), \delta 157.0,151.3$ and $140.6(\mathrm{~s}, \mathrm{C}=\mathrm{C}), \delta 113.9(\mathrm{~s}$,

$\mathrm{N}-\mathrm{C}=\mathrm{C}-), \delta 77.2(\mathrm{~d}, \mathrm{~N}-\mathrm{CH}-), \delta=54.9\left[\mathrm{~s},-\mathrm{C}(\mathrm{E}) \mathrm{CH}_{2} \mathrm{E}\right], \delta 52.6$, $52.4,51.7$ and $51.3\left(\mathrm{q}, \mathrm{OCH}_{3}\right), 851.9\left(\mathrm{t}, \mathrm{N}-\mathrm{CH}_{2}\right), 636.9,36.6$ and 35.0 (t, 2x $\mathrm{CH}_{2} \mathrm{E}$ and $=\mathrm{C}-\mathrm{C}-$ ), $\delta 26.1,25.7$ and 24.1 (t, other $\left.-\mathrm{CH}_{2}\right)$. IR (KBr): 1710, 1732 and $1742(\mathrm{sh}) \mathrm{cm}^{-1}(\mathrm{C}=0)$, $1612 \mathrm{~cm}^{-1}\left(-\mathrm{C}=\mathrm{C}-\right.$ ). $\mathrm{MS}: \mathrm{M}^{+}$421.174, Calc. 421.174 . (Found: $\mathrm{C}$, 60.17; $\mathrm{H}, 6.55 ; \mathrm{N}, 3.26$. Calc. for $\mathrm{C}_{21} \mathrm{H}_{27} \mathrm{NO}_{2}$ (421.45): C, 59.85; $\mathrm{H}$, $6.46 ; N, 3.32 \%)$.

Reaction of 1-(1 - pyrrolidinyl)cycloherene (9) with two equivalents of DMAD

Formation of $[2,3,5,6,7,8,9,9 \mathrm{a}$ - octahydno - 9 - (methoxycarbonyl) - 9 - (methoxycarbonylmethyl) - $1 \mathrm{H}$ - pymolo[1,2-a]indol 5 - ylidene] - butanedioic acid dimethyl ester (15). Compound 15 was prepared as described for 14. GC-analysis (10\% SE-30) of the crude mixture showed, in addition to 15 , the presence of $33 \%$ of 12, which could not be isolated by chromatography because of decomposition on silica. Yield $46 \%$; m.p. 133.5-134; ; $\mathrm{H}$ NMR: $\delta$

4.51 (dd, $J=6 \pm 1$ and $9 \pm 1 \mathrm{~Hz}, \mathrm{~N}-\mathrm{CH}$ ), $\delta 4.48$ and 3.73 (AB-q, $\left.J=17 \mathrm{~Hz},=\mathrm{C}-\mathrm{CH}_{2} \mathrm{E}\right), \delta 3.73$ and $3.68\left(\mathrm{~s}, 12 \mathrm{H}, \mathrm{OCH}_{3}\right), \delta 3.30$ and $2.51\left(\mathrm{AB}-\mathrm{q}, J=17 \mathrm{~Hz},-\mathrm{CH}_{2} \mathrm{E}\right) .{ }^{3} \mathrm{C}$ NMR: $\delta 173.5,172.2,171.8$ and $168.7(\mathrm{~s}, \mathrm{C}=\mathrm{C}), \delta 146.7$ and $141.9(\mathrm{~s}, \mathrm{~N}-\mathrm{C}=$ and $\mathrm{C}=\mathrm{C}), \delta 121.6$ and 119.1 (s, $\mathrm{N}-\mathrm{C}=\mathrm{C}$ and $\mathrm{C}=\mathrm{C}$ ), $\delta 69.1$ (d, N-CH-), $\delta 57.7$ [s, $\left.-\mathrm{C}(\mathrm{E}) \mathrm{CH}_{2} \mathrm{E}\right], \delta 52.4,52.2,51.8$ and $51.3\left(\mathrm{q}, \mathrm{OCH}_{3}\right), \delta 51.6(\mathrm{t}$, $\left.\mathrm{N}-\mathrm{CH}_{2}\right), \delta 36.4$ and $36.1\left(\mathrm{t}, \mathrm{CH}_{2} \mathrm{E}\right), \delta 30.0,27.3,24.9,24.3$ and $21.6\left(\mathrm{t}\right.$, other $\left.-\mathrm{CH}_{2}-\right)$. IR $(\mathrm{KBr}): 1740$ and $1748(\mathrm{sh}) \mathrm{cm}^{-1}(\mathrm{C}=\mathrm{C})$, 1608 and $1631 \mathrm{~cm}^{-1}(-C=C-)$. MS: $M^{+} 435.191$, Calc. 435.189 . (Found: $\mathrm{C}, 60.70 ; \mathrm{H}, 6.81 ; \mathrm{N}, 3.17$. Calc. for $\mathrm{C}_{22} \mathrm{H}_{29} \mathrm{NO}_{8}$ (435.48): C, $60.68 ; H, 6.71 ; \mathrm{N}, 3.22 \%$ ).

Reaction of 1 - (1 - pyrrolidinyl)cyclopentene (8) with methyl propiolate

Formation of 2 - (1 - pyrrolidinyl) - 1 - cyclopentene - 1 . propenoic acid methyl ester (17). A soln of methyl propiolate $(0.67 \mathrm{~g}, 8 \mathrm{mmol})$ in $10 \mathrm{ml} \mathrm{MeOH}$ was added to a soln of $8(0.69 \mathrm{~g}$. $5 \mathrm{mmol}$ ) in $15 \mathrm{ml} \mathrm{MeOH}$ under $\mathrm{N}_{2}$ at $-20^{\circ}$. (The resulting solid dissolved at about $0^{\circ}$.) After stirring for $2 \mathrm{hr}$ at room temp, the $\mathrm{MeOH}$ was removed under reduced pressure. The red oil was crystallized from diethyl ether at $-20^{\circ}$ yielding the pure 17 as orange needles. Yield 73\%; m.p. 77-77.5'; 'H NMR: $\delta 7.99$ (d, $J=14 \mathrm{~Hz},=C-H C=), \delta 5.16(\mathrm{~d}, J=14 \mathrm{~Hz},=\mathrm{CHE}), \delta 3.70(\mathrm{~s}$, $\left.\mathrm{OCH}_{3}\right), \delta 3.7-3.5\left(\mathrm{~m}, 4 \mathrm{H}, \mathrm{N}-\mathrm{CH}_{2}\right), \delta 2.8-2.45\left(\mathrm{~m}, 4 \mathrm{H},=\mathrm{C}-\mathrm{CH}_{2}\right)$ and $\delta$ 2.1-1.75 (m, 6 H, $\left.-\mathrm{CH}_{2}\right)$. ${ }^{13} \mathrm{C}$ NMR: $\delta 169.5(\mathrm{~s}, \mathrm{C}=0)$, $\delta$ $154.6(\mathrm{~s}, \mathrm{~N}-\mathrm{C}=), \delta 141.5(\mathrm{~d},=\mathrm{C}-\mathrm{HC}=), \delta 104.2(\mathrm{~s}, \mathrm{~N}-\mathrm{C}=\mathrm{C}), \delta 103.9$ $(\mathrm{d},=\mathrm{CHE}), \delta 5.11\left(\mathrm{t}, \mathrm{N}-\mathrm{CH}_{2}\right), \delta 50.6\left(\mathrm{q}, \mathrm{OCH}_{3}\right), \delta 36.6$ and 32.3 $\left(\mathrm{t},=\mathrm{C}-\mathrm{CH}\right.$ ) and $\delta 25.4$ and $20.7\left(\mathrm{t},-\mathrm{CH}_{2}-\mathrm{l}\right.$. IR $(\mathrm{KBr}): 1695 \mathrm{~cm}^{-1}$ $(C=0)$. MS: $M^{*} 221.141$, Calc. 221.142. (Found: $C, 70.46 ; H, 8.60$; $\mathrm{N}, 6.22$. Calc. for $\mathrm{C}_{13} \mathrm{H}_{19} \mathrm{NO}_{2}$ (221.30): C, 70.56; H, 8.65; N, $6.33 \%)$.

†All reievant crystallographic data are deposited at the Cambridge Crystallographic Data Centre (C.C.D.C.).
Reaction of 5,5 - dimethyl - 3-(1-pyrnolidinyl) - 2- cyclohexen 1 - one (18) with DMAD in propylene carbonate

Fomation of 5,5 - dimethyl - 7 - oxo - 3 - (1 - pyrrolidinyl) - 2,8 - cyclooctadiene - 1,2 - dicartoxylic acid dimethyl ester (19) and $4,4$ - dimethyl - 6 - oxo - 2-(1-pyrrolidinyl $)-1$ - cyclohexene - 1 - butenedioic acid dimethyl ester (20). DMAD $(2.84 \mathrm{~g}, 20 \mathrm{mmol})$ was added dropwise to a soln of $18(3.86 \mathrm{~g}, 20 \mathrm{mmol})$ in $25 \mathrm{ml}$ propylene carbonate under $\mathrm{N}_{2}$ at $0-5^{\circ}$. After $1 \mathrm{hr}$ at $0^{\circ}$, the soln was stired overnight at room temp. The solvent was removed under reduced pressure $(0.01 \mathrm{~mm} \mathrm{Hg})$ and the residue was separated by column chromatography (silica gel, EtOAc) yielding $19(10 \%)$ and $20(37 \%)$. Compound 19 was purified by recrystallization from hexane and 20 by elution with EtOAc.

Compound 19; ${ }^{30}$ Yield 10\%; m.p. 120.5-122.5 . 'H NMR (Py$\left.d_{3}\right): \delta 6.87(\mathrm{~s},=\mathrm{CH}), \delta 3.81$ and $3.73\left(\mathrm{~s}, \mathrm{OCH}_{3}\right), \delta 3.6-3.3(\mathrm{~m}$, $\left.\mathrm{N}-\mathrm{CH}_{2}-\right), \delta 3.14$ and $2.08\left(\mathrm{AB}-\mathrm{q}, J=11 \mathrm{~Hz}, \mathrm{CH}_{2}-\mathrm{C}=\right), \delta 2.61$ and $2.34\left(\mathrm{AB}-\mathrm{q}, J=14 \mathrm{~Hz}, \mathrm{CH}_{2}-\mathrm{C}=0\right), \delta 1.8-1.5\left(\mathrm{~m}, 4 \mathrm{H}, \mathrm{N}-\mathrm{CH}_{z}\right.$ $\left.\mathrm{CH}_{2}\right), \delta 1.00\left(\mathrm{~s}, 6 \mathrm{H}, \mathrm{CH}_{3}\right) .{ }^{13} \mathrm{C}$ NMR: $\delta 170.4$ and $164.6(\mathrm{~s}, \mathrm{C}=0)$ $\delta 161.3(\mathrm{~s}, \mathrm{~N}-\mathrm{C}=), \delta 144.2(\mathrm{~s}, \mathrm{~N}-\mathrm{C}=\mathrm{C}-\mathrm{C}=), \delta 130.1(\mathrm{~d},=\mathrm{CH}), \delta$ $96.0(\mathrm{~s}, \mathrm{~N}-\mathrm{C}=\mathrm{C}), \delta 52.6$ and $50.9\left(\mathrm{q}, \mathrm{OCH}_{3}\right), \delta 52.0\left(\mathrm{t}, \mathrm{N}-\mathrm{CH}_{2}-\right), \delta$ $39.0\left[\mathrm{~s}, \mathrm{C}\left(\mathrm{CH}_{3}\right)\right], \delta 29.4$ and $28.5\left(\mathrm{q}, \mathrm{CH}_{3}\right), \delta 25.2\left(\mathrm{t}, \mathrm{N}-\mathrm{CH}_{2}\right.$ $\left.\mathrm{CH}_{2}\right)$. IR (KBr): 1723 and $1708 \mathrm{~cm}^{-1}\left(\mathrm{C}=0\right.$, ester), $1640 \mathrm{~cm}^{-1}$ ( $C=0$, ketone). MS: $M^{+} 335.173$, Calc. 335.173 .

Compound 20; Yield 37\%; m.p. 132-134'. 'H NMR: 85.35 (s, $=\mathrm{CH}), \delta 3.80$ and $3.73\left(\mathrm{~s}, \mathrm{OCH}_{3}\right), \delta 3.36\left(\mathrm{~s}, \mathrm{br}, 4 \mathrm{H}, \mathrm{N}-\mathrm{CH}_{2}\right), \delta$ $2.54\left(\mathrm{~s}, \mathrm{CH}_{2}-\mathrm{C}=\right), \delta 2.20\left(\mathrm{~s}, \mathrm{CH}_{2}-\mathrm{C}=0\right), \delta 1.95(\mathrm{~s}, \mathrm{br}, 4 \mathrm{H}$, $\left.\mathrm{N}-\mathrm{CH}_{2}-\mathrm{CH}_{2}\right), \delta 1.08$ (s, 6 H, $\left.\mathrm{CH}_{3}\right)$. ${ }^{3} \mathrm{C}$ NMR: $\delta 193.9$ (s, $\mathrm{C}=0$, ketone), $\delta 168.5$ and 166.1 (s, $\mathrm{C}=0$, esters), $\delta 161.9$ (s, N-C=), $\delta$ $144.0(\mathrm{~s},-\mathrm{EC}=), \delta 120.0(\mathrm{~d},=\mathrm{CH}), \delta 106.7(\mathrm{~s}, \mathrm{~N}-\mathrm{C}=\mathrm{C}), \delta 51.9$ and $51.5\left(\mathrm{~g}, \mathrm{OCH}_{3}\right), \delta 49.8\left(\mathrm{t}, \mathrm{N}-\mathrm{CH}_{2}\right), \delta 30.6\left[\mathrm{~s},-\mathrm{C}^{2}\left(\mathrm{CH}_{3}\right)\right], \delta 28.3$ and $28.2\left(\mathrm{q}, \mathrm{CH}_{3}\right)$. IR $(\mathrm{KBr}): 1745$ and $1715 \mathrm{~cm}^{-1}(\mathrm{C}=0$, ester $)$ and $1620 \mathrm{~cm}^{-1}\left(C=0\right.$, ketone). MS: $M^{+} 335.173$, Calc. 335.173 . (Found: C, 64.66; H, 7.57; N. 4.05. Calc. for $\mathrm{C}_{18} \mathrm{H}_{25} \mathrm{NO}$, (335.41): C. $64.46 ; \mathrm{H}, 7.51 ; \mathrm{N}, 4.18 \%$ ).

$X$-Ray structure determination of 14. The structure of 14 was determined from 2882 significant inlensities $(I>\sigma(I))$ measured on a Philips PW 1100 diffractometer, using graphitemonochromated MoK $\alpha$ radiation. The $6 / 2 \theta$ scan mode was used in the range $3<\theta<25^{\circ}$. The total number of independent reflections measured was 3139 . The unit cell parameters found were: $a=13.269$ (4), $b=22.413$ (4), $c=7.293$ (2) $A, \beta=102.90$ $(3)^{\circ}, Z=4, d_{c}=1.33 \mathrm{~g} \mathrm{~cm}^{-3}$. The space group is $P 2 / \mathrm{c}$. The structure was solved by direct methods ${ }^{26}$ and refined with anisotropic temp factors for the non-H atoms. A difference Fourier Synthesis made at this stage revealed maxima at the positions of all possible $H$ positions. In the next cycles of refinement all $H$ atoms were included. During these refinements two $\mathrm{H}$ atoms got very high temp factors and shifted to physically unacceptable positions. For this reason the temp factors of these atoms were kept constant and only their position parameters were refined.t The resulting R-factor was $5.4 \%$.

Acknowledgement-We are grateful for the financial support of this work by the "Koningin Wilhelmina Fonds". The authors wish to express their gratitude to Mrs. J. L. M. Klop-Vrielink and Miss J. M. Visser for recording the NMR spectra and to Mr. T. W. Stevens for recording the mass spectra.

\section{REFERENCES}

I. V. Jaeger and H. G. Viehe, Houben-Weyl, Methoden der Organischen Chemie, 4th Edn (Edited by E. Mueller), Vol. V/2a, p. 8140. Georg Thieme Verlag, Stuttgart (1977).

${ }^{16} R$. Fuks and H. G. Viehe, Chemistry of Acetylenes (Edited by H. G. Viehe), p. 425. Marcel Dekker, New York (1969).

2. J. Ficini, A. Eman and A. M. Touzin, Tetrahedron Letters 679 (1976); 'J. Ficini, J. d'Angelo, A. Eman and A. M. Touzin, Ibid. $683(1976)$

${ }^{3}$ A. D. de Wit, M. L. M. Pennings, W. P. Trompenaars, D. N. Reinhoudt, S. Harkema and O. Nevestveit, J. Chem. Soc. Chem. Comm. 993 (1979).

4a). M. Lukas, F. Baardman and A. P. Kouwenhoven, Angew. Chem. Int. Ed. Engl. 15, 369 (1976); ' B. B. Snider, D. J. Rodini. 
R. S. E. Conn and S. Sealfon, J. Am. Chem. Soc. 101, 5283 (1979); ' H. Fienemann and H. M. R. Hoffmann, J. Org. Chem. 44. 2802 (1979); 'D. N. Reinhoudt, H. C. Volger, C. G. Kouwenhoven, H. Wijnberg and R. Helder, Tetrahedron Letters 5269 (1972).

'For leading references see: A. G. Cook, Enamines, Synthesis, Structure and Reactions (Edited by A. G. Cook), p. 211. Marcel Dekker, New York (1969); M. Baumgarth, Chem. Ztg. 101, 118 (1977) and E. Winterfeldt, Angew. Chem. 79, 389 (1967).

${ }^{6} \mathrm{~V}$. Jaeger and H. G. Viehe, Ibid. 82, 836 (1970).

${ }^{7}$ K. C. Brannock, R. D. Burpitt, V. W. Goodlett and J. G. Thweatt, J. Ong. Chem. 28, 1464 (1963).

'G. A. Berchtold and G. F. Uhlig, Ibid. 28, 1459 (1963).

${ }^{9}$ C. F. Huebner, L. Dorfman, M. M. Robison, E. Donoghue, W. G. Pierson and P. Strachan, Ibid. 28, 3134 (1963).

${ }^{10}$ D. Becker, L. R. Hughes and R. A. Raphael, J. Chem. Soc. Perkin I 1674 (1977).

${ }^{11}$ G. Stork and T. L. Macdonald, J. Am. Chem. Soc. 97, 1264 (1975).

${ }^{12}$ D. N. Reinhoudt, Adv. Heterocycl. Chem. 21, 253 (1977).

${ }^{13}$ D. N. Reinhoudt and C. G. Kouwenhoven, Recl. Trav. Chim. Pays-Bás 93, 129 (1973).

${ }^{14} \mathrm{D}$. N. Reinhoudt and C. G. Kouwenhoven, Tetrahedron 30. 2093 (1974).

${ }^{13}$ D. N. Reinhoudt, J. Geevers, W. P. Trompenaars, S. Harkema and G. J. van Hummel, J. Ong. Chem. 46, 424 (1981).

${ }^{16}$ The preliminary results of this investigation have been published, see: D. N. Reinhoudt, J. Geevers and W. P. Trompenaars, Tetrahedron Letters 1351 (1978).

${ }^{17}$ L. M. Long, J. Am. Chem. Soc. 68, 2159 (1946).

${ }^{18}$ S. Karlsson and J. Sandstroem, Acta Chem. Scand. B 32, 141 (1978).

${ }^{19}$ D. N. Reinhoudt, G. Okay, W. P. Trompenaars, S. Harkema, D. M. W. van den Ham and G. J. van Hummel, Tetrahednon Letters 15:9 (1979).

${ }^{20}$ Besides $(2+2)$-cycloaddition linear Michael addition is frequently observed. ${ }^{2123}$ The ratio of these reaction rates is also dependent on the polarity of the solvent. ${ }^{21.23}$

${ }^{21}$ K. C. Brannock, R. D. Burpitt, V. W. Goodlett and J. G. Thweatt, J. Org. Chem. 29, 818 (1964).

${ }^{22} \mathrm{C}$. Hubschwerlen, J. P. Fleury and H. Fritz, Tetrahedron 32, 3031 (1976).

${ }^{23} \mathrm{~W}$. Eberbach and J. C. Carré, Tetrahedron Letters 21, 1145 (1980).

${ }^{24}$ D. J. Robins, Adv. Heterocycl. Chem. 24, 247 (1979).

${ }^{25}$ E. Yoshii and S. Kimoto, Chem. Pharm. Bulletin 17, 629 (1969).

${ }^{26} \mathrm{G}$. Germain, P. Main and M. M. Woolfson, Acta Cryst. A27, 368 (1971).
${ }^{n 7}$ C. K. Johnson, ORTEP, Report ORNL-3794, Oak Ridge National Laboratory, Tennessee (1965).

T. W. Doyle, Can. J. Chem. 48, 1633 (1970).

IJ. Geevers, G. W. Visser and D. N. Reinhoudt, Recl. Trav. Chim. Pays-Bas \%, 251 (1979).

${ }^{30}$ E. J. Cone, R. H. Garner and A. W. Hayes, Tetrahedron Letters 57 (1972).

${ }^{31}$ After completion of this work we noticed the work of Reiss ${ }^{32}$ who studied the influence of substituents on cycloaddition reactions in general including $(2+2)$-cycloaddition of enamines with acetylenes. His tentative conclusion is that the reaction proceeds via a 1,4-dipolar intermediate.

${ }^{32}$ K. Reiss, Ph.D. Thesis, p. 81. Muenchen (1978).

${ }^{330} \mathrm{R}$. Huisgen, Acc. Chem. Res. 10, 117 (1977); ${ }^{\circ} \mathrm{R}$. Huisgen, Ibid. 10, 199 (1977).

${ }^{34}$. Fleming, Frontier Orbitals and Organic Chemical Reactions, p. 23. Wiley, London (1976).

${ }^{33}$ Doyle ${ }^{36}$ has put forward the idea of a concerted $(2+2+2)$ cycloaddition for reaction of olefins and acetylenes.

${ }^{36}$ T. W. Doyle, Can. J. Chem. 48, 1629 (1970).

${ }^{37 a} \mathrm{R}$. Huisgen, Angew. Chem. 92, $979(1980) ;{ }^{b}$ E. C. Taylor and I. J. Turchi, Chem. Rev. 79, 181 (1979).

${ }^{38}$ K. Hafner, H.-G. Klaes and M. C. Boehm, Tetrahedron Letters 21, 41 (1980).

${ }^{39} \mathrm{~N}$. Anghelide, C. Draghici and D. Raileanu, Tetrahedron 30, 623 (1974).

4The reactions of 3-(1-pyrrolidinyl)thiophenes with DMAD in acetonitrile show the opposite. There the relative yield of pyrrolizine decreases with increasing reaction temp. However in acetonitrile the activation entropy for the formation of the solvated charge-separated dipole will be much more negative since it involves the organization of solvent molecules that are not organized in free solvent. Alcohols however are organized in solution by $\mathbf{H}$-bonds and solvation of a dipolar transition state will hardly increase the organization of the system (see for a detailed discussion Huisgen and Steiner ${ }^{41}$ ).

${ }^{41} \mathrm{G}$. Steiner and R. Huisgen, Tetrahedron Letters 3769 (1973).

${ }^{42}$ G. Siork, A. Brizzolara, H. Landesman, J. Szmuszkovicz and R. Terrell, J. Am. Chem. Soc. 85, 207 (1963).

${ }^{43}$ F. A. van der Vlugt, J. W. Verhoeven and U. K. Pandit, Recl. Trav. Chim. Pays-Bas 89, 1258 (1970).

${ }^{4}$ N. J. Leonard and J. A. Adamcik, J. Am. Chem. Soc. 81, 595 (1959).

${ }^{45}$ Methanol adds to DMAD to give a mixture of dimethyl methoxyfumarate and maleate (Compare: E. Winterfeldt and H. Preuss, Chem. Ber. 99, 450 (1966)). However in our cases this reaction is slow compared with reactions of DMAD and enamines.

${ }^{*}$ The other doublet was hidden under other peaks. 